Revista Brasileira de Meteorologia, v.28, n.3, 246 - 256, 2013

\title{
ANÁLISE MICROCLIMÁTICA EM DUAS FITOFISIONOMIAS DO CERRADO NO ALTO VALE DO JEQUITINHONHA, MINAS GERAIS
}

\author{
ANDRÉ RODRIGUES DA CUNHA GIANOTTI ${ }^{1}$, MARIA JOSÉ HATEM DE SOUZA ${ }^{2}$, EVANDRO \\ LUIZ MENDONÇA MACHADO ${ }^{1}$, ISRAEL MARINHO PEREIRA ${ }^{1}$; ARTHUR DUARTE VIEIRA ${ }^{1}$; \\ MARIANA RODRIGUES MAGALHÃES ${ }^{1}$;
}

\author{
${ }^{1}$ Universidade Federal dos Vales do Jequitinhonha e Mucuri (UFVJM), Departamento de Engenharia \\ Florestal, Diamantina, MG, Brasil \\ ${ }^{2}$ UFVJM, Departamento de Agronomia, Diamantina, MG, Brasil
}

andre-rcg@hotmail.com, mariahatem@yahoo.com.br, machadoelm@gmail.com, imarinhopereira@gmail. com, arthur.duartevieira@gmail.com,magalhaesflorestal@hotmail.com

Recebido Maio de 2012 - Aceito Janeiro de 2013

\begin{abstract}
RESUMO
O clima e o solo tem uma estreita relação com a vegetação de uma determinada localidade. Visando entender melhor essa dinâmica no ambiente do cerrado, este estudo teve como objetivo avaliar na região de Diamantina, Vale do Jequitinhonha, MG, a interação dos elementos climáticos entre fitofisionomias de Campo Rupestre e Cerrado Rupestre, assim como relacionar as características edáficas, e florísticas com o clima. Os elementos climáticos utilizados para caracterizar os ambientes de cerrado foram a temperatura, a umidade relativa do ar, a pressão real e de saturação do vapor de água, o déficit de pressão do vapor do ar, a velocidade e a direção do vento, a precipitação, a radiação solar global e a amplitude térmica. Utilizaram-se para tanto os dados obtidos em duas estações meteorológicas automáticas localizadas próximas aos dois ambientes. O ambiente de Campo Rupestre se distingue do Cerrado Rupestre, principalmente pela maior velocidade do vento, menor umidade relativa do ar máxima, menor pressão real e de saturação do vapor de água, menor temperatura máxima e média e menor amplitude térmica. O efeito em conjunto das variáveis climáticas, somado ao embasamento geológico aparente, discutidos neste estudo, justifica a diferença fitofisionômica observada entre o Cerrado Rupestre e o Campo Rupestre.

Palavras-chave: Savana.Variáveis ambientais. Análise multivariada.
\end{abstract}

\begin{abstract}
MICROCLIMATIC ANALYSIS OF TWO PHYSIOGNOMIES OF SAVANNAH IN THE HIGH VALLEY JEQUITINHONHA, MINAS GERAIS, BRAZIL

The climate and soil have a close relationship with the vegetation of a particular locality. In order to better understand this dynamic environment of the Brazilian Cerrado, this study aimed to evaluate in the region of Diamantina, high valley of Jequitinhonha, Minas Gerais, Brazil, the interaction between climate variables and the physiognomies of the Rupestrian Savannah and the Rupestrian Field environments and also relate the soil characteristics and species composition with the weather conditions. The climate variables used to characterize the Savannah environments were: temperature; relative humidity; actual and saturated vapor pressure; vapor pressure deficit; wind speed and direction; rainfall; incoming solar radiation; and temperature amplitude. For such analysis, data from two weather stations located close to the two environments were used. The Rupestrian Field distinguished from the Rupestrian Savannah mainly because of the higher wind speed, lower maximum relative humidity, lower actual and saturation vapor pressure, lower maximum and average temperature and lower temperature amplitude. The overall effect of climatic variables plus the geologic considerations discussed, in this study, justifies the physiognomy differences found between the Rupestrian Savannah and the Rupestrian Field. keywords: Savannah. Multivariate analysis. Environmental variables.
\end{abstract}




\section{INTRODUÇÃO}

As coberturas vegetais dominantes na Cadeia do Espinhaço são formações de cerrado, com vegetação que cresce sobre pedregulhos ou rochas, em solos rasos ou pedregosos de origem recente, ou ainda em depósitos arenosos (Kamino et al., 2008). Alguns autores (Oliveira-Filho e Fluminhan-Filho, 1999, Nakajima e Romero 1999, Romero e Martins 2002) citam raras espécies espalhadas nesses ambientes de altitudes distribuídos pelo Brasil. Dessa forma, é de se esperar que as características climáticas e que o embasamento geológico aparente influenciem na distribuição arbórea dessas áreas do bioma Cerrado, e em consequência, no padrão florístico.

Wang et al. (2006), trabalhando com as dez maiores florestas no nordeste da China, mostraram que o clima controla a distribuição das espécies dominantes em uma área. Kamino et al. (2008) utilizaram-se da análise multivariada para correlacionar clima e 18 áreas florestais localizadas na Cadeia do Espinhaço, e as variáveis mais fortemente correlacionadas com a fitofisionomia foram a temperatura, vinculada à altitude, e o regime de precipitação. Neri et al. (2007) observaram que padrões florísticos formados nas áreas de cerrado são explicados em primeiro lugar pelas variáveis climáticas e em segundo pelos fatores do solo.

No cerrado brasileiro, a precipitação pluviométrica varia de 800 a 2000 mm com uma estação seca bem definida de variada amplitude durante o inverno, e as temperaturas médias anuais variam de 18 a $28^{\circ} \mathrm{C}$ (Dias, 1996).

Diante desse contexto, cresce o interesse na caracterização ambiental do bioma cerrado, envolvendo aspectos climáticos e edáficos, na busca de estabelecer correlações entre tais características e ocorrências das espécies vegetais.

Com base no exposto, este trabalho teve como objetivos: a) caracterizar na região de Diamantina, Alto Vale do Jequitinhonha, $\mathrm{MG}$, a variação espacial e temporal dos elementos climáticos em dois ambientes distintos: Campo Rupestre e Cerrado Rupestre; b) fazer uma análise comparativa dos elementos climáticos nesses dois ecossistemas de cerrado e correlacioná-los à caracterização da vegetação e ao embasamento geológico aparente.

\section{MATERIAIS E MÉTODOS}

O estudo foi conduzido no município de Diamantina, Alto Vale do Jequitinhonha, MG, localizado na região do Espinhaço Meridional, com predominância de solos arenosos com baixo poder de retenção de umidade em termos gerais, entremeando os grandes afloramentos rochosos, conforme Abreu et al. (2005).

O clima da região segundo a classificação Köppen é Cwb, temperado úmido, com inverno seco e chuvas no verão.
A temperatura média anual é de $18,3^{\circ} \mathrm{C}$, a média das mínimas é $14,1^{\circ} \mathrm{C}$ e a média das máximas de $23,7^{\circ} \mathrm{C}$; sendo a temperatura média do mês mais quente de $20,1^{\circ} \mathrm{C}$. A insolação média anual é de 6,55 horas.dia ${ }^{-1}$, e velocidade média do vento de $2,37 \mathrm{~m} \cdot \mathrm{s}^{-1}$ com direção predominante NE (Normais Climatológicas do Brasil, de 1961 a 1990 - INMET, 2009). A precipitação média anual é de $1404 \mathrm{~mm}$, e o período chuvoso ocorre de outubro a março e representa $88 \%$ do total precipitado durante o ano (Vieira et al., 2010). Segundo o Balanço hídrico climatológico de Thornthwaite e Mather (1955), a evapotranspiração potencial anual é de $819 \mathrm{~mm}$, o excedente hídrico anual é de $661 \mathrm{~mm}$ e a deficiência hídrica anual de 75 mm (EMBRAPA, 2003). A vegetação predominante da região são formações de cerrado.

Neste trabalho estudou-se a área de "Campo Rupestre" e a de "Cerrado Rupestre", segundo as classificações propostas por Ribeiro e Walter (2008). Ambas são vegetações predominantes da região e fazem parte das formações do Bioma Cerrado. Nesses trechos altos da Cadeia do Espinhaço, há uma maior similaridade vegetacional em relação àquelas observadas nas Chapadas dos Veadeiros (GO) ou dos Guimarães (MT), devido à influência dos biomas contíguos (Walter, 2006). Rigonato (2005) adotou a expressão "Cerrado rupestre de altitude", empregada por Ribeiro e Walter (2008) como "Cerrado Rupestre". No entanto, segundo Walter (2006) não há informações claras sobre qual espécie ocorre nos Campos Rupestres e no Cerrado Rupestre no sentido de Ribeiro e Walter (2008).

A vegetação de Campo Rupestre localiza-se na altitude de $1387 \mathrm{~m}, 18^{\circ} 10^{\prime} \mathrm{S}$ de latitude e $43^{\circ} 30^{\prime} \mathrm{W}$ de longitude e encontra-se no Campus Juscelino Kubitschek (JK) da Universidade Federal dos Vales do Jequitinhonha e Mucuri (UFVJM). Já a vegetação de Cerrado Rupestre localiza-se no Sítio Santa Helena, a $18^{\circ} 17^{\prime}$ S de latitude, $43^{\circ} 34^{\prime} \mathrm{W}$ de longitude e com altitude de $1149 \mathrm{~m}$. O sentido fisionômico campestre, ou campo, são referentes às áreas que tem o predomínio de espécies herbáceas e algumas arbustivas, faltando árvores na paisagem; já o termo Cerrado Rupestre refere-se à fisionomia savana, áreas com árvores e arbustos espalhados sobre um extrato de gramíneas, sem a formação de dossel contínuo (Ribeiro e Walter, 2008). Na Figura 1, pode ser visualizada a localização espacial dos dois ambientes de estudo e fotos ilustrativas dos ambientes e das estações.

O levantamento florístico foi feito com a locação de um bloco amostral de 1 ha para os dois ambientes de estudo, dividido em subparcelas contiguas de $1000 \mathrm{~m}^{2}$ (20x50 m). As espécies foram identificadas por comparação com exsicatas do Herbário Dendrológico Jeanini Felfili (HDJF) da Universidade Federal dos Vales do Jequitinhonha e Mucuri.

A amostragem de solo foi feita com a coleta de 6 amostras simples em cada subparcela, formando uma amostra composta, totalizando dessa forma dez amostras compostas para 


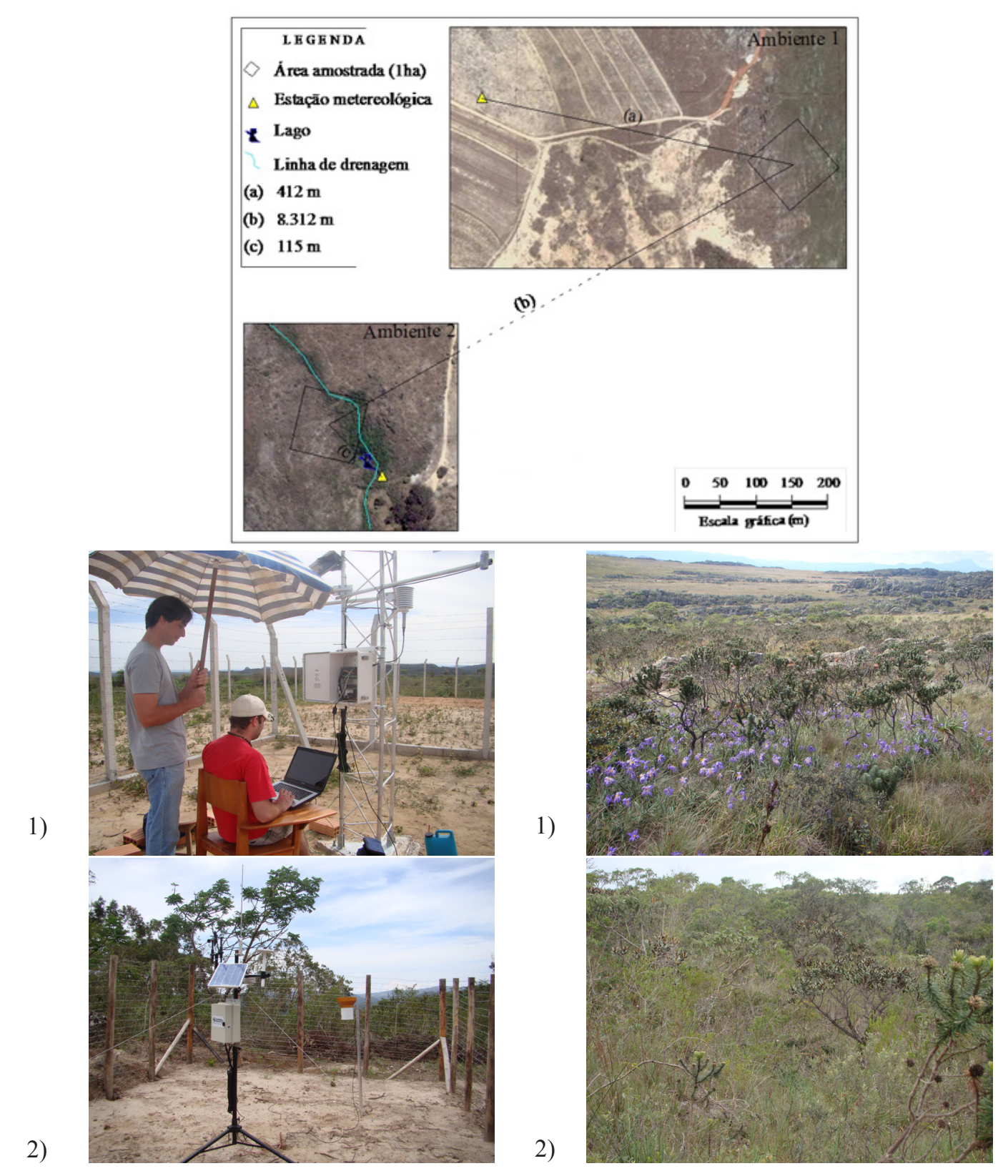

Figura 1 - Ilustração das distâncias dos ambientes de estudo, das estações meteorológicas e o ambiente circunvizinho; ambiente (1) Campo Rupestre e ambiente (2) Cerrado Rupestre.

Fonte: Imagens disponibilizadas no Google Earth. Desenho: Josiane Silva Bruzinga.

cada bloco amostral nos dois ambientes de estudo, segundo orientações de Ribeiro et al. (1999). Coletou-se o solo a uma profundidade entre 0 a $20 \mathrm{~cm}$, buscando áreas sem a exposição de rochas, que poderiam impedir a coleta nessa profundidade. As amostras após a coleta foram encaminhadas para o laboratório de Ciências do Solo da Universidade Federal de Viçosa, onde foram realizadas as análises químicas e físicas.

$\mathrm{O}$ embasamento geológico aparente foi definido com a proporção do ambiente com rocha aflorada usando-se a escala de Braun-Blanquet utilizada por Moura et al. (2011). Determinou-se visualmente o percentual de cobertura da área da parcela por rochas (nível 1:0-25\%, nível 2: 26-50\%, nível 3: 51-75\% e nível 4:76-100\%).

O clima dos ambientes de cerrado foi caracterizado utilizando-se dados coletados durante o ano de 2010 nos dois ambientes, obtidos em duas estações automáticas instaladas nos dois ambientes de estudo. Com base nesses dados, utilizaram-se valores médios mensais da velocidade do vento, da temperatura 
máxima, mínima e média, da umidade relativa do ar (máxima, mínima e média), da pressão de saturação de vapor de água, da pressão real de vapor de água, do déficit de pressão de vapor de ar e da radiação solar global; e do total precipitado mensalmente para a caracterização microclimática.

A pressão real de vapor de água (ea) foi estimada com base na pressão de saturação de vapor de água (es), a qual é função da temperatura ambiente, e da umidade relativa do ar (Pereira et al., 2002).

As variáveis microclimáticas, a partir da verificação de uma distribuição normal, foram submetidas à análise de variância Teste-T. Segundo Santana e Ranal (2004), em uma situação na qual as observações não correspondem à distribuição normal, o teste Kruskall Wallis é o recomendado. Dessa forma, empregou-se o teste Kruskal-Wallis para a variável umidade relativa do ar máxima para comparar os dois ambientes em estudo. Para realização desses testes empregou-se o programa BioEstat 5.0.

\section{RESULTADOS E DISCUSSÃO}

No ambiente de Cerrado Rupestre foram encontradas espécies com alturas maiores, com 3,2 m em média, como por exemplo: Eremanthus incanus (Asteraceae); Kielmeyera lathrophyton (Clusiaceae); Terminalia sp. (Combretaceae); Vochysia discolor (Vochysiaceae); Bowdchia virgilioides (Fabaceae); Cupania sp. (Sapindaceae); Myrsine guianensis (Myrtaceae); Xylopia aromática (Annonaceae); entre outras. Já as espécies Protium spruceanum (Burseraceae), Protium heptaphyllum (Burseraceae), Xylopia sericea (Annonaceae), Calophyllum brasiliense (Clusiaceae), Tapirira guianensis (Anacardiaceae) foram encontradas nas áreas úmidas do Cerrado Rupestre exclusivamente dentro de Mata da Galeria inundada.

No ambiente de Campo Rupestre a vegetação constituiu-se de arbustos com altura média de 1,2 m e possivelmente fitomassa foliar inferior à observada no Cerrado Rupestre, com predominância de: Lychnophora pohlii; Eremanthus glomerulatus; Palicourea rígida; Byrsonima sp.; Eremanthus incanus. É importante ressaltar que o ambiente amostrado de Campo Rupestre obteve 58,8\% dos elementos da sua flora no ambiente Cerrado Rupestre, destacando-se o estrato subarbustivo-herbácio.

Na Figura 2 são apresentados os valores mensais da temperatura do ar média, mínima e máxima, e da amplitude térmica. A Figura 3 apresenta a variação mensal da umidade relativa do ar, média, mínima e máxima, da pressão real de vapor de água (ea), da pressão de saturação de vapor de água (es), e do déficit de pressão de vapor do ar (es - ea), nos dois ambientes

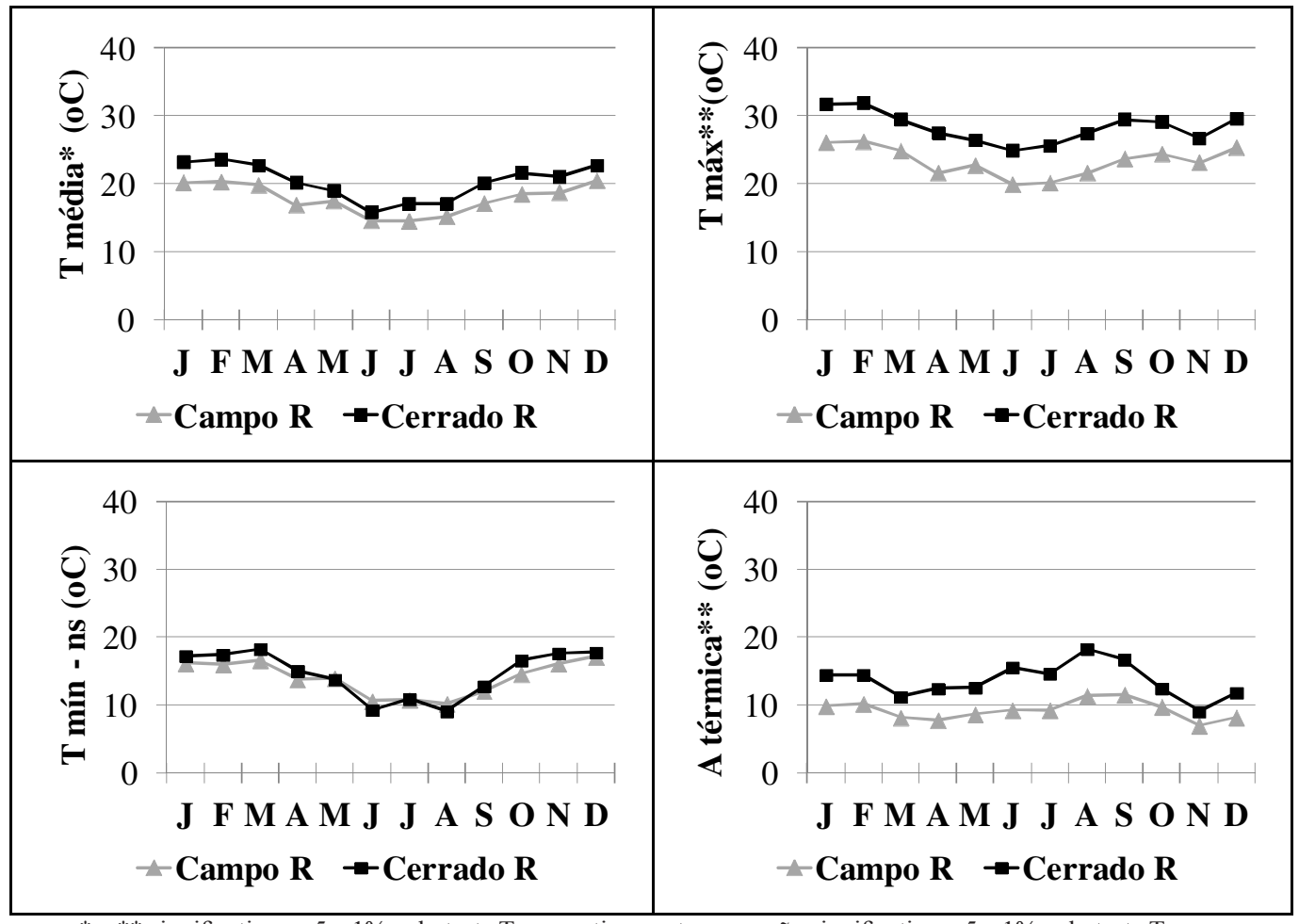

* e ** $^{*}$ significativos a 5 e $1 \%$ pelo teste T, respectivamente; n.s. não significativo a 5 e $1 \%$ pelo teste T.

Figura 2 - Valores mensais da temperatura do ar, média, máxima e mínima, e da amplitude térmica, nos dois ambientes estudados no ano de 2010. * e e* $^{*}$ significativos a 5 e $1 \%$ pelo teste-T , respectivamente; n.s. não significativo a 5 e $1 \%$ pelo teste-T. 
estudados. Já na Figura 4 são apresentados os valores mensais da radiação solar global, da precipitação total, da velocidade do vento a $2 \mathrm{~m}$ de altura, e a frequência relativa da direção do vento nos dois ambientes estudados. Os valores apresentados nas Figuras 2 a 4 também podem ser visualizados na Tabela 1, juntamente com a significância estatística e com as direções predominantes do vento em cada mês do ano de 2010, no ambiente do Cerrado Rupestre e do Campo Rupestre.

Observa-se, nas Figuras 2 a 4 e na Tabela 1, variação semelhante dos elementos climáticos nos dois ambientes, os quais seguem as mesmas tendências ao longo do ano, uma vez que são interligados pelo mesmo regime climático ao qual estão submetidos os dois ambientes.

As temperaturas do ar mais elevadas (Figura 2) ocorrem na estação chuvosa (outubro a março) e consequentemente as maiores pressões de vapor são observadas neste período (Figura 3). Em contrapartida, menores temperaturas e pressões de vapor d'água são observadas na estação de seca (abril a setembro) (Figuras 2 e 3). Em ambos os ambientes os menores valores de umidade relativa do ar são observados nos meses de agosto a outubro e, em consequência, maiores valores de déficit de pressão de vapor também ocorrem nesse período (Figura 3), meses que precedem o início da estação chuvosa (Figura 4). Nesses meses também são evidentes os altos valores de radiação solar global (Figura 4), provavelmente devido a uma menor nebulosidade somada ao aumento gradual no ângulo de elevação solar em relação ao período de abril a julho.

A estação seca na região ocorre de abril a setembro, e representa $12 \%$ do total da chuva anual. O trimestre mais chuvoso é o de novembro a janeiro, sendo este último mês

Tabela 1 - Valores dos atributos climáticos e o nível de significância estatística, nos dois ambientes de estudo: Campo Rupestre (CaR) e Cerrado Rupestre (CeR),

\begin{tabular}{|c|c|c|c|c|c|c|c|c|c|c|c|c|c|c|c|c|}
\hline & \multirow{2}{*}{\multicolumn{2}{|c|}{$\begin{array}{c}\mathbf{P}(\mathrm{ns}) \\
\mathbf{m m}\end{array}$}} & \multicolumn{2}{|c|}{ Tmed * } & \multicolumn{2}{|c|}{$\operatorname{Tmax} * *$} & \multicolumn{2}{|c|}{$\begin{array}{c}\text { T mín } \\
\text { (ns) }\end{array}$} & \multicolumn{2}{|c|}{$\begin{array}{l}\text { Amplitude } \\
\text { Térmica** }\end{array}$} & \multicolumn{2}{|c|}{ URméd* } & \multicolumn{2}{|c|}{ URmáx* } & \multicolumn{2}{|c|}{ URmín* } \\
\hline & & & \multicolumn{2}{|c|}{${ }^{\circ} \mathrm{C}$} & \multicolumn{2}{|c|}{${ }^{\circ} \mathbf{C}$} & \multicolumn{2}{|l|}{${ }^{\circ} \mathbf{C}$} & \multicolumn{2}{|c|}{${ }^{\circ} \mathrm{C}$} & \multicolumn{2}{|c|}{$\%$} & \multicolumn{2}{|c|}{$\%$} & \multicolumn{2}{|c|}{$\%$} \\
\hline & $\mathrm{CaR}$ & CeR & $\mathrm{CaR}$ & CeR & $\mathrm{CaR}$ & CeR & $\mathrm{CaR}$ & CeR & $\mathrm{CaR}$ & CeR & $\mathrm{CaR}$ & CeR & CaR & CeR & CaR & CeR \\
\hline Jan & 33 & 43,5 & 20,2 & 23,2 & 26,1 & 31,7 & 16,2 & 17,2 & 9,9 & 14,5 & 73 & 77 & 92 & 100 & 50 & 42 \\
\hline Fev & 3,5 & 28,9 & 20,3 & 23,6 & 26,2 & 31,9 & 16 & 17,4 & 10,2 & 14,5 & 72 & 74 & 92 & 99 & 48 & 40 \\
\hline Mar & 202,8 & 154,5 & 19,8 & 22,7 & 24,8 & 29,5 & 16,6 & 18,3 & 8,2 & 11,2 & 81 & 84 & 95 & 100 & 61 & 54 \\
\hline Abr & 26,8 & 46 & 16,9 & 20,2 & 21,6 & 27,5 & 13,8 & 15,1 & 7,8 & 12,4 & 81 & 84 & 95 & 100 & 60 & 52 \\
\hline Mai & 57,1 & 30,2 & 17,5 & 19 & 22,7 & 26,4 & 14 & 13,8 & 8,7 & 12,6 & 79 & 86 & 93 & 100 & 56 & 54 \\
\hline Jun & 1 & 8 & 14,6 & 15,8 & 19,9 & 24,9 & 10,6 & 9,3 & 9,3 & 15,6 & 73 & 83 & 90 & 100 & 52 & 48 \\
\hline Jul & 3,8 & 5,2 & 14,5 & 17,1 & 20,1 & 25,6 & 10,8 & 10,9 & 9,3 & 14,7 & 76 & 80 & 95 & 100 & 51 & 44 \\
\hline Ago & 0 & 0 & 15,2 & 17,1 & 21,6 & 27,4 & 10,2 & 9,1 & 11,4 & 18,3 & 63 & 71 & 84 & 99 & 38 & 33 \\
\hline Set & 6,1 & 6,4 & 17,1 & 20,1 & 23,7 & 29,5 & 12,1 & 12,8 & 11,6 & 16,7 & 64 & 69 & 87 & 97 & 39 & 34 \\
\hline Out & 121,5 & 125 & 18,5 & 21,6 & 24,4 & 29,1 & 14,6 & 16,6 & 9,8 & 12,5 & 77 & 80 & 94 & 99 & 53 & 49 \\
\hline Nov & 276,2 & 187,5 & 18,7 & 21 & 23,1 & 26,7 & 16,1 & 17,6 & 7 & 9,1 & 85 & 89 & 97 & 100 & 65 & 62 \\
\hline Dez & 310,6 & 237,2 & 20,5 & 22,7 & 25,4 & 29,6 & 17,1 & 17,7 & 8,2 & 11,8 & 79 & 83 & 93 & 100 & 57 & 54 \\
\hline \multirow[t]{4}{*}{ ANO } & 1042,4 & 872,4 & 17,8 & 20,3 & 23,3 & 28,3 & 14 & 14,7 & 9,3 & 13,7 & 75,2 & 80 & 92,1 & 99,4 & 52,5 & 47,2 \\
\hline & \multicolumn{2}{|c|}{ es * } & \multicolumn{2}{|c|}{ ea * } & \multicolumn{2}{|c|}{ es - ea (ns) } & \multicolumn{3}{|c|}{$\begin{array}{l}\text { Velocidade } \\
\text { Vento*** }\end{array}$} & \multicolumn{5}{|c|}{$\begin{array}{l}\text { Direção Predominante do } \\
\text { Vento }\end{array}$} & \multicolumn{2}{|c|}{ Rg (ns) } \\
\hline & \multicolumn{2}{|c|}{ kPa } & \multicolumn{2}{|c|}{$\mathbf{k P a}$} & & $\mathrm{kPa}$ & & $\mathbf{m} / \mathbf{s}$ & & & Ocorrê & ncia ( & \%) & & $\mathbf{M J} /\left(\mathrm{m}^{2}\right.$ & 2.dia) \\
\hline & CaR & CeR & CaR & CeR & $\mathrm{CaR}$ & CeR & $\mathrm{CaF}$ & & $\mathrm{CeR}$ & & aR & & CeR & & $\mathrm{CaR}$ & CeR \\
\hline Jan & 2,4 & 2,8 & 1,7 & 2,2 & 0,6 & 0,7 & 2 , &, 4 & 0,2 & & E $(48 \%$ & & NE $\left(41^{\circ}\right.$ & & 23,9 & 23,2 \\
\hline Fev & 2,4 & 2,9 & 1,7 & 2,2 & 0,7 & 0,7 & 2 , &, 5 & 0,2 & & E $(41 \%$ & & $\mathrm{NE}\left(39^{\circ}\right.$ & & 22,5 & 22 \\
\hline Mar & 2,3 & 2,8 & 1,9 & 2,3 & 0,4 & 0,4 & 2 , &, 2 & 0,2 & & J $\quad(35 \%$ & & NE $\left(39^{\circ}\right.$ & & 17,3 & 18 \\
\hline Abr & 1,9 & 2,4 & 1,6 & 2 & 0,4 & 0,4 & 2 , &, 2 & 0,1 & & E $(29 \%$ & & NE $\left(22^{\circ}\right.$ & & 15,6 & 16,8 \\
\hline Mai & 2 & 2,2 & 1,6 & 1,9 & 0,4 & 0,3 & 1 , & ,9 & 0,1 & & N $(38 \%$ & & NE $\left(30^{\circ}\right.$ & & 15 & 15,7 \\
\hline Jun & 1,7 & 1,8 & 1,2 & 1,5 & 0,5 & 0,3 & 1 , & ,9 & 0,1 & & E $(23 \%$ & & NE $(21$ & & 16,4 & 15,7 \\
\hline Jul & 1,7 & 1,9 & 1,3 & 1,6 & 0,4 & 0,4 & 2 , &, 3 & 0,1 & & $(33 \%$ & & NE $(32$ & & 16,1 & 17,8 \\
\hline Ago & 1,7 & 1,9 & 1,1 & 1,4 & 0,6 & 0,6 & 2 , &, 1 & 0,2 & & E $(34 \%$ & & NE $(34$ & & 20,3 & 24,1 \\
\hline Set & 1,9 & 2,4 & 1,3 & 1,6 & 0,7 & 0,7 & 2 , & 6 & 0,3 & & IE $(44 \%$ & & NE (41 & & 24,6 & 26 \\
\hline Out & 2,1 & 2,6 & 1,6 & 2,1 & 0,5 & 0,5 & 2 , &, 5 & 0,4 & & $\mathrm{E}(35 \%$ & & NE (48 & & 25,6 & 19,8 \\
\hline Nov & 2,2 & 2,5 & 1,8 & 2,2 & 0,3 & 0,3 & 2 , &, 5 & 0,3 & & IE $(30 \%$ & & NE $(55$ & & 16,5 & 16,4 \\
\hline Dez & 2,4 & 2,8 & 1,9 & 2,3 & 0,5 & 0,5 & 2 , &, 5 & 0,3 & $\mathrm{~N}$ & J $(27 \%$ & & NE $(48$ & & 21,9 & 21,9 \\
\hline ANO & 2,1 & 2,4 & 1,6 & 1,9 & 0,5 & 0,5 & 2 , & 3 & 0,2 & $\mathrm{NE}$ & $(31,4 \%$ & & $\operatorname{NE}(37,4$ & & 19,6 & 19,8 \\
\hline
\end{tabular}

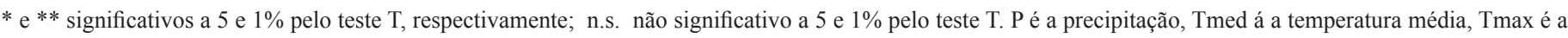

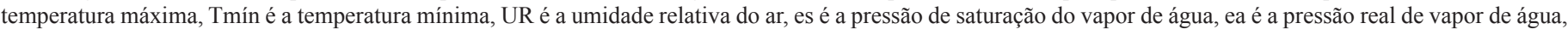
es - ea é o déficit de pressão de vapor de água e Rg é a radiação solar global.
} 


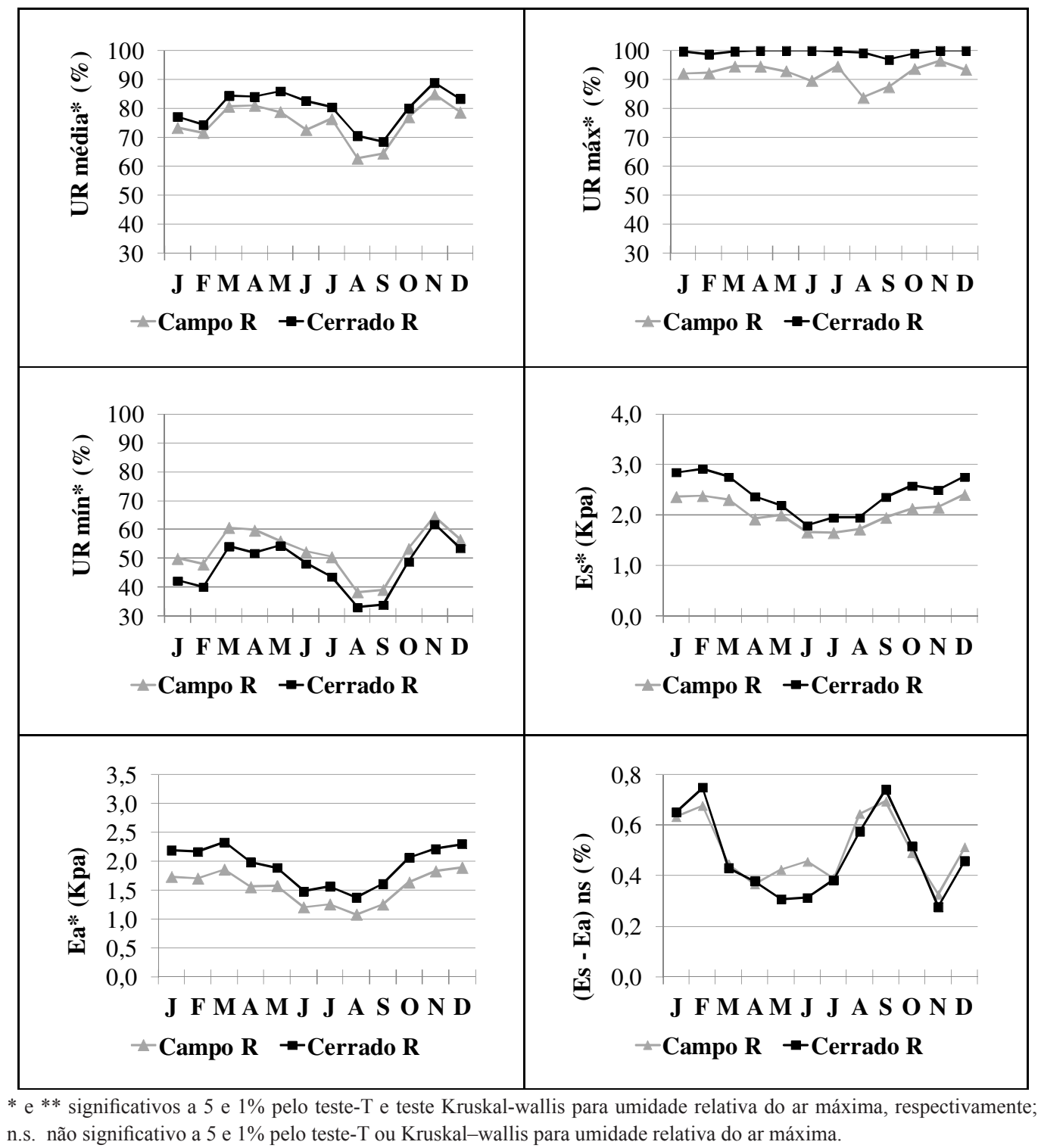

Figura 3 - Valores mensais da umidade relativa do ar (UR), média, máxima e mínima em \%; pressão de saturação de vapor (es), pressão real de vapor (ea) e déficit de pressão de vapor (es - ea), nos dois ambientes estudados no ano de 2010 . * e** significativos a 5 e $1 \%$ pelo teste-T e teste Kruskal-wallis para umidade relativa do ar máxima, respectivamente; n.s. não significativo a 5 e 1\% pelo teste-T ou Kruskal-wallis para umidade relativa do ar máxima.

o de maior precipitação $(307 \mathrm{~mm})$, de acordo com os dados climáticos de Diamantina (Vieira et. al., 2010). No ano de 2010, os meses de menores valores precipitados também ocorreram de abril a setembro nos dois ambientes e os maiores ocorreram em dezembro, novembro e, março (Figura 4). Já os meses de janeiro e fevereiro neste ano específico, de 2010, tiveram um valor muito inferior quando comparados com os dados das normais climatológicas. No Campo rupestre a precipitação em janeiro foi de $33 \mathrm{~mm}$ e em fevereiro de $3,5 \mathrm{~mm}$, e no Cerrado rupestre foi de $13,5 \mathrm{~mm}$ em janeiro e de $28,9 \mathrm{~mm}$ em fevereiro; enquanto que os dados normais são da ordem de 307 e 121 mm, respectivamente.
Observa-se também, nas Figuras 2 a 4 e na Tabela 1, que houve diferença significativa pelo Teste-T nos dois ambientes, para as variáveis: temperatura máxima, temperatura média, amplitude térmica (Figura 2), velocidade do vento (Figura 4), pressão real e de saturação de vapor. Já a umidade relativa do ar máxima apresentou diferença significativa pelo teste não paramétrico Kruskal-Wallis (Figura 3), demonstrando assim que para essas variáveis os dois ambientes são distintos.

Com relação à precipitação total mensal, não se verificou diferença significativa pelo Teste $\mathrm{T}$ no período de estudo para os dois ambientes (Figura 4), mesmo quando testada para os 


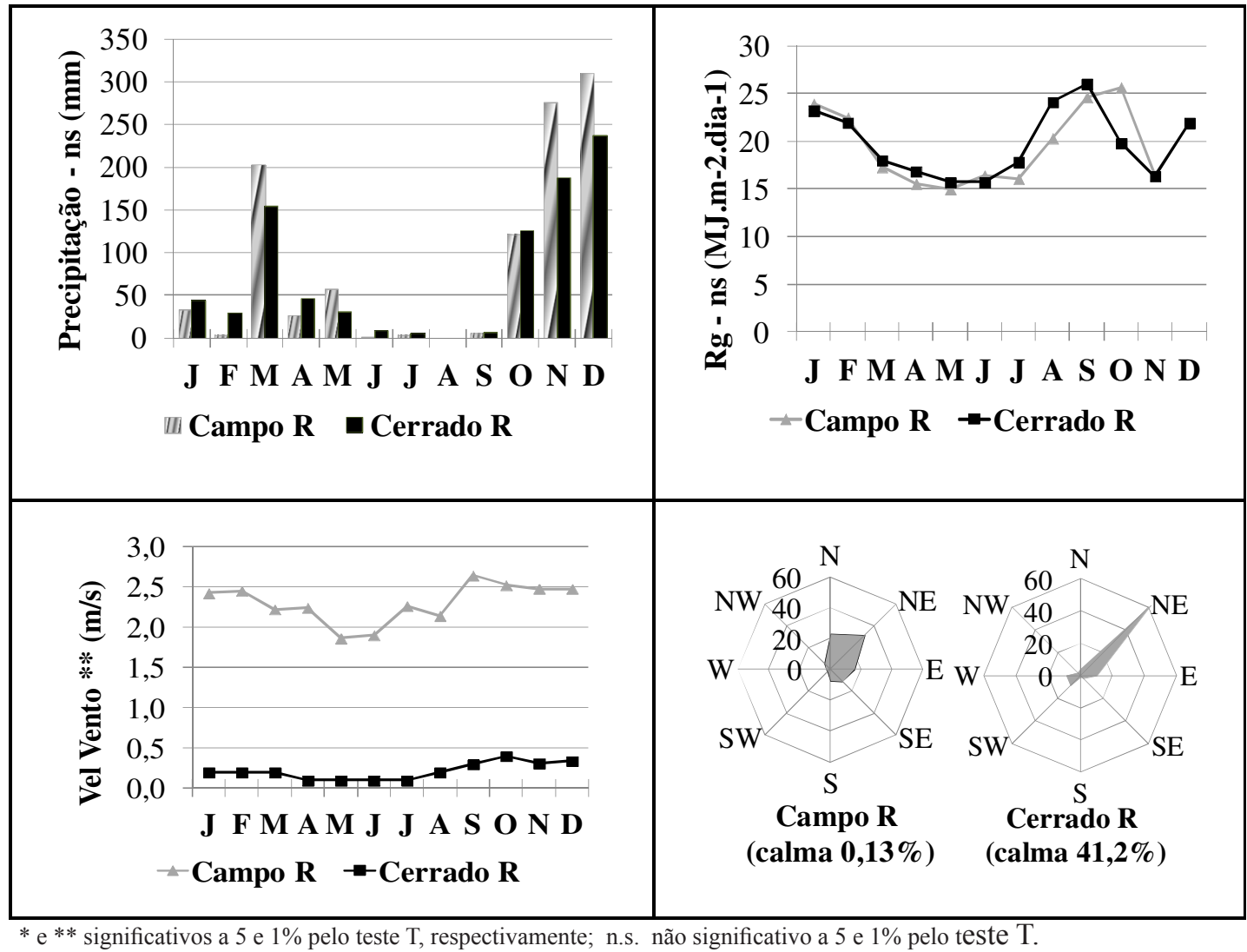

Figura 4 - Valores mensais de precipitação total, da radiação solar global (Rg), da velocidade e frequência relativa da direção do vento a 2 metros de altura, em 2010, nos dois ambientes de estudo Campo Rupestre (Campo R) e Cerrado Rupestre (Cerrado R). ** e** significativos a 5 e $1 \%$ pelo teste $\mathrm{T}$, respectivamente; n.s. não significativo a 5 e $1 \%$ pelo teste $\mathrm{T}$.

seis meses da estação chuvosa (EC), ou seja, outubro a março, e para os seis meses da estação seca (ES), de abril a setembro. Ainda, no intuito de averiguar a diferença significativa para a variável precipitação, que visivelmente parece existir nos meses de março, outubro, novembro e dezembro, testou-se essa quadra mais chuvosa não havendo significância entre os dois ambientes.

Esse resultado demonstra que somente a precipitação não define o tipo de vegetação de um local, resultado que difere dos obtidos por Kamino et. al. (2008). Esses autores mostraram que um dos principais fatores climáticos que influenciam a ocorrência e distribuição espacial das fisionomias florestais da Cadeia do Espinhaço é a precipitação pluvial. Wang et al. (2006), trabalhando com as dez maiores florestas no nordeste da China, mostraram que o fator precipitação é o que controla a distribuição das espécies dominantes em uma área. Entretanto, esses autores relatam vegetações arbóreas de ambientes distintos em relação aos do presente estudo. Eles utilizaram nos estudos ambientes distanciados a centenas e até milhares de quilômetros, o que difere do trabalho aqui estudado, no qual os dois ambientes estão sujeitos ao mesmo padrão de precipitação, uma vez que estão no mesmo domínio climático, distanciando de $8,3 \mathrm{~km}$ em linha reta (Figura 1).

Observa-se na Figura 4 que no período de junho a setembro as precipitações foram extremamente baixas ou inexistentes nos dois ambientes, a umidade relativa do ar máxima (Figura 3) foi maior, ao longo desses meses, no ambiente Cerrado Rupestre, quando comparado ao ambiente de Campo Rupestre. Este fato pode ser explicado, por um lado, pela textura do solo, que no ambiente de Cerrado Rupestre possui maiores teores de matéria orgânica e argila, dois elementos que tem notada influência na capacidade de retenção de água no solo, do que no Campo Rupestre, no qual o solo é mais arenoso, retendo assim menos água. Por outro lado, sabe-se que a umidade relativa do ar esta diretamente associada à temperatura do ar, nesse caso, é provável que o microclima do Cerrado Rupestre tenha influenciado para que estes valores de umidade relativa máxima tenham sido maiores (Figura 1).

A área de Campo Rupestre apresenta um teor menor de matéria orgânica e argila com 1,28 dag $/ \mathrm{kg}$ e $5 \%$ respectivamente, do que no Cerrado Rupestre, que tem 4,88 dag/kg e $13 \%$. Sabe-se que quanto menor a retenção de água no solo, menor a 
evapotranspiração (Lima et al., 2001). Em resposta a tal fator estressante, as plantas reduzem o fluxo de vapor d'água do interior da câmara subestomática para a atmosfera, causando redução na transpiração (Thomas et al., 2000). Entretanto, Voigt et al. (2010), revisando alguns trabalhos clássicos sobre o cerrado, alerta para a existência de uma grande variação de respostas na taxa de transpiração das plantas às oscilações na disponibilidade hídrica do ambiente.

A velocidade do vento a 2 metros de altura é significativamente maior, ao nível de $1 \%$ pelo Teste-T, no ambiente de Campo Rupestre (Figura 4) ocasionando, dessa forma, maior remoção do vapor de água da vegetação influenciando assim a umidade relativa máxima (Figura 2). Com relação à direção predominante do vento esta é de NE para os dois ambientes (Figura 4 e Tabela 1). No Cerrado Rupestre a predominância do vento NE é de $61,7 \%$, enquanto que no Campo Rupestre é de 31,4\%, seguida pelo vento de $\mathrm{N}$ (com 23,2\%). A alta predominância do vento de NE no Cerrado Rupestre esta associada à localização da estação que se encontra em uma clareira, cercada por árvores nos quadrantes S, L e W e com uma encosta abaixo voltada para N e NE. Enquanto que no ambiente do Campo Rupestre a estação esta localizada em um dos pontos mais altos da região. $\mathrm{Na}$ estação pertencente ao INMET e localizada no aeroporto da cidade (1362 $\mathrm{m}$ de altitude, latitude de $18^{\circ} 13^{\prime} \mathrm{S}$ e longitude $\left.43^{\circ} 38^{\prime} \mathrm{W}\right)$. Souza e Cupollilo (2012), obtiveram resultados semelhantes em que o vento de nordeste (NE) prevalece durante o dia e o vento SE durante a noite.

A pressão real de vapor de água (ea) obteve, em parte, reflexos em virtude dessas características do solo, pois nesse período de estudo essa variável apresentou valores superiores em relação ao Campo Rupestre (Figura 3). Isso ocorre, porque solos que têm maior capacidade de armazenamento de água, são capazes de manter uma taxa maior de evapotranspiração por um período mais longo, segundo Chang (2006), refletindo assim no aumento da pressão real de vapor na atmosfera.

No Cerrado Rupestre há uma maior densidade de elementos lenhosos com maiores alturas, e possivelmente com sistemas radiculares mais profundos e, em consequência, maiores fitomassas foliares quando comparado ao Campo Rupestre (Figura 1). Os reflexos desses fatores podem levar a um maior consumo das reservas de água do subsolo no ambiente de Cerrado Rupestre, contribuindo para um aumento da evapotranspiração e, por conseguinte, maior pressão real de vapor na superfície e maior umidade relativa do ar média (Figura 3). No Campo Rupestre a carência das espécies florestais expõe mais a superfície do solo aos efeitos da radiação solar e do vento, aumentando, dessa forma, a evaporação, refletindo, consequentemente, em uma menor pressão real de vapor e proporcionando no ambiente de Cerrado Rupestre uma maior umidade relativa máxima (Figura 3).

No ambiente Campo Rupestre, ocorrem as maiores velocidades do vento (Figura 4) devido à maior altitude, o que favorece a remoção de vapor das camadas próximas à superfície para as camadas mais altas da atmosfera, resultando em decréscimo da concentração de vapor de água próximo à superfície e, em consequência, menores valores de umidade relativa do ar e pressão de vapor de água (Figura 3). Pereira et al. (2002), ao apresentarem a variação temporal da umidade relativa do ar em Piracicaba, SP, comentaram que a relação entre a intensidade dos ventos e pressão real de vapor de água na superfície é inversamente proporcional, mas ressaltaram que isso ocorre desde que o ar não esteja saturado de água.

Segundo Carlesso (1995), o suprimento de água às plantas é determinado pela habilidade da cultura em utilizar a água armazenada no solo, enquanto a demanda da atmosfera, por outro lado, está relacionada à combinação dos fatores meteorológicos interagindo com o dossel vegetativo da cultura. Chang (2006) explica que se o potencial hídrico nos estômatos é maior do que o do ar, a água dos estômatos é vaporizada para o ar devido ao déficit de pressão de vapor (es - ea). Entretanto, não houve diferença significativa pelo Teste-T quanto ao déficit de saturação de vapor (es - ea), para os dois ambientes (Figura 3).

A variação da umidade relativa do ar nos dois ambientes (Figura 3) está interligada de forma inversamente proporcional, durante a maior parte do ano, com as variações mensais da temperatura do ar (Figura 2 e 3). Este fato é comum em meteorologia e pode ser explicado fisicamente da seguinte forma: quanto maior a temperatura do ar, maior a capacidade do ar de conter vapor de água e maior pressão de saturação de vapor de água (es). Como es é inversamente proporcional à umidade relativa do ar, maiores temperaturas proporcionam menores umidades relativas do ar. Andrade et al. (2009), na Amazônia, estudaram a variação dos elementos micrometeorológicos acima da vegetação em ambiente de floresta e de cerrado (transição), e verificaram uma relação inversamente proporcional entre temperatura e umidade relativa do ar.

Durante a estação seca, a diferença das temperaturas médias entre o Cerrado Rupestre e o Campo Rupestre foi de $2,1^{\circ} \mathrm{C}$ (Figura 4 e 2). Na estação chuvosa, nos meses de outubro a maio, a diferença média foi de $2,7^{\circ} \mathrm{C}$ entre o Cerrado Rupestre e o Campo Rupestre, o que pode ser explicado em parte pela diferença de altitude, pois o ambiente de Cerrado Rupestre apresenta menor altitude, 1149 m, em relação ao Campo Rupestre, 1387 m. De acordo com a variação vertical da temperatura do ar nos limites da troposfera, apresentada por Sellers (1974), existe uma redução média de $0,65^{\circ} \mathrm{C}$ a cada 100 $\mathrm{m}$ de elevação acima do nível da superfície. São cerca de 240 metros de diferença de altitude, o que poderia resultar, se não 
houvesse interferência de outras variáveis microclimáticas, em um gradiente adiabático de cerca de $1,6^{\circ} \mathrm{C}$ entre os dois ambientes.

Kamino et al. (2008) relatam que, em variadas formações florestais, na Serra do Espinhaço, a temperatura média anual vinculada à altitude exerce uma forte influência no padrão das espécies e, consequentemente, na caracterização da fitofisionomia.

Outro ponto determinante para isso está relacionado com uma maior velocidade do vento (Figura 4) para o ambiente de Campo Rupestre, uma vez que o vento atua diretamente no clima de uma área, removendo calor das plantas e do ambiente, aumentando assim a evapotranspiração, resultando em redução da temperatura.

Ao observar os efeitos do vapor de água na retenção de calor, Chang (2006) verificou a influência direta deste, ou seja, quanto maior a pressão de vapor de água, maior a capacidade de armazenamento de calor no ambiente, ou seja, quando as temperaturas caem durante os períodos noturnos, o calor armazenado pelo vapor de água modela as temperaturas mínimas refletindo em valores maiores na temperatura média para o ambiente de Cerrado Rupestre (Figura 2). Rosenberg et al. (1983) comentam que a radiação é máxima no comprimento de onda de 10 micrometros, faixa espectral em que o vapor de água tem grande influência na absorção da radiação terrestre, e consequentemente reduz a sua fuga para o espaço, aumentando assim a energia terrestre.

A radiação solar global ( $\mathrm{Rg}$ ) não diferiu estatisticamente pelo Teste-T nos dois ambientes (Figura 4), e os maiores valores ocorreram durante a estação chuvosa, meses de maior elevação solar. Vourlitis et al. (2008) relatam que a maior incidência de radiação solar global no período das águas é uma resposta à variação anual do ângulo de incidência da radiação solar global. Esses, por sua vez, são parcialmente refletidos e absorvidos pelo solo, pelas plantas e pela atmosfera local, sendo, posteriormente, convertida em energia térmica.

No mês de novembro, há um decréscimo da radiação solar global ocasionando uma pequena diminuição na temperatura máxima. Notadamente, nesse período ocorreram chuvas na região, resultando menor incidência de radiação quando o céu está nublado, uma vez que as nuvens atuam difundindo e refletindo parte da radiação que atinge a superfície terrestre, como observado nas Figuras 2 e 4 . A temperatura máxima mais amena no mês de novembro também é ocasionada pela precipitação, que converte o calor sensível do ar em calor latente nas superfícies molhadas, ocasionando uma redução na temperatura.

Observa-se após as análises e interpretação dos dados de temperatura do ar que a altitude é um importante controlador da temperatura do ar na área do Campo Rupestre. No entanto, o ambiente de Cerrado Rupestre apresentou, durante o período de junho a agosto, as menores temperaturas mínimas, apesar dessas serem esperadas para o Campo Rupestre. Essa condição pode ser explicada pelo escoamento do ar frio, mais denso, para as partes mais baixas, acumulando-se nas proximidades do ambiente de Cerrado Rupestre amostrado. Vale ressaltar que é justamente nessa área que está localizado o ponto autorizado para instalação da estação meteorológica utilizada neste estudo. É comum o escoamento do ar frio nesta época do ano, principalmente no período noturno e nestas condições topográficas, resultando em situações de inversão térmica. Galvini et al. (2010) após o estudo climático em uma variação altimétrica de 1793 metros, no Parque Nacional do Caparaó (ES), concluíram que a configuração do perfil topográfico é um importante controlador do clima em relação à ocorrência do processo de inversão térmica.

A maior amplitude térmica, tanto para o Campo Rupestre, quanto para o Cerrado Rupestre, foi observada nos meses de junho a setembro, ou seja, durante a estação seca (Figura 2). Nesses meses, a diferença média entre as temperaturas máximas e mínimas foi de $16,3^{\circ} \mathrm{C}$ para o Cerrado Rupestre e $10,4^{\circ} \mathrm{C}$ para o Campo Rupestre, enquanto nos meses de outubro a maio a diferença média foi de, respectivamente, $12,3{ }^{\circ} \mathrm{C}$ e $8,7^{\circ} \mathrm{C}$, para o Cerrado Rupestre e para o Campo Rupestre.

Esse comportamento térmico está relacionado com a menor quantidade de nuvens durante os meses da estação seca, proporcionando assim uma maior incidência de radiação solar durante o dia e uma maior perda energética radioativa da superfície durante a noite. A amplitude térmica também está relacionada à umidade, de modo que uma maior umidade relativa do ar ocasiona uma menor amplitude térmica, devido ao elevado calor específico da água, que atua como controlador térmico (Andrade et al., 2009). Esse fato pode ser verificado entre as diferentes estações (menor amplitude em meses da estação chuvosa).

A menor velocidade do vento (Figura 4) para o ambiente de Cerrado Rupestre, provavelmente proporcionou uma menor remoção de calor do ambiente, refletindo em maiores temperaturas máximas e maiores amplitudes térmicas (Figura 2).

Oliveira-filho e Fluminhan-filho (1999) comentam que os afloramentos rochosos favorecem uma grande amplitude térmica, tanto ao longo do dia, como entre as estações do ano. Apesar do percentual da área coberta por rochas (embasamento geológico aparente) ser maior no ambiente de Campo Rupestre em relação ao ambiente de Cerrado Rupestre, com 31 e 4,8\% respectivamente, esse fator não foi suficiente para proporcionar um aumento na amplitude térmica. No entanto, o fato de o nível de exposição natural em superfície de rocha ser maior, interfere em um ambiente de menor profundidade de solo, o que pode acarretar, devido às precipitações intensas, 
enxurradas e consequentemente maior lixiviação de nutrientes em relação ao ambiente de Cerrado Rupestre, dificultando o desenvolvimento das plantas. Sabe-se que a deficiência de nutrientes nas plantas causa efeitos graves ao metabolismo da planta, como o crescimento retardado. Dessa forma pode-se observar que a expressão da vegetação se dá em virtude de fatores climáticos e também do embasamento geológico aparente, desse modo as coberturas vegetais são diferentes nesses ambientes.

\section{CONCLUSÃO}

O ambiente de Campo Rupestre se distingue significativamente do Cerrado Rupestre principalmente em relação à maior velocidade do vento, menor umidade relativa do ar máxima, menor pressão real e de saturação de vapor de água, menor temperatura máxima e média e menor amplitude térmica.

Diante do exposto, pode-se inferir que os elementos climatológicos estudados atuam em conjunto, sendo seus efeitos observados de forma distinta no que se refere aos ambientes em posições geográficas diferentes, o que influencia os valores dessas variáveis climáticas.

Dessa forma, o efeito em conjunto das variáveis climáticas, somado ao embasamento geológico aparente, discutidos neste estudo, justifica a diferença fitofisionômica observada entre o Cerrado Rupestre e o Campo Rupestre.

\section{AGRADECIMENTOS}

À Coordenação de Aperfeiçoamento de Pessoal de Nível Superior (CAPES) pela concessão de Bolsa de estudo do primeiro autor, e à Fundação de Amparo à Pesquisa do Estado de Minas Gerais (FAPEMIG) pelo apoio financeiro na execução desta pesquisa.

\section{REFERÊNCIAS}

ABREU, P. A. A.; FRAGA, L. M. S.; NEVES, S. C. Geologia. In: Silva, A. C.; Pedreira, L. V. S. F.; Abreu, P. A. A. Serra do Espinhaço Meridional, paisagens e ambientes. Belo Horizonte: O Lutador, Cap.1. 17-45. 2005.

ANDRADE, N. L. R.; AGUIAR, R. G.; SANCHES, L.; ALVES, E. C. R. F.; NOGUEIRA, J. S. Partição do saldo de radiação em áreas de floresta Amazônica e floresta de transição Amazônia-Cerrado. Revista Brasileira de Meteorologia, v. 24, n. 3, 346-355, 2009.

CARLESSO, R. Absorção de água pelas plantas: água disponível versus extraível e a produtividade das culturas. Revista Ciência Rural, Santa Maria, v.25, n.1, p.183-188, 1995.
CHANG, M. Functions of water. In: Forest Hydrology: an introduction to water and forest / Mingteh Chang. $-2^{\text {nd }}$ ed. Texas: Taylor \& Francis, p. 5-22, 2006.

DIAS, B. F. S. Alternativas de desenvolvimento dos cerrados: manejo e conservação dos recursos naturais não renováveis. 2.ed. Brasília: Fundação Pró-Natureza, 97p. 1996.

EMBRAPA Monitoramento por Satélite. Empresa Brasileira de Pesquisa Agropecuária. Banco de dados climáticos do Brasil. Disponível em: <www.bdclima.cnpm.embrapa.br/ resultados/balanco.php? $\mathrm{UF}=\& \mathrm{COD}=87>$. Atualizado em 5 de setembro de 2003. Acesso em: 29 ago. 2012.

GALVANI, E.; LIMA, N. G. B.; FALCÃO, R. M. Ocorrência de inversão térmica no perfil topoclimático do Pico da Bandeira, Parque Nacional do Alto Caparaó, Brasil. Departamento de Geografia, Universidade de São Paulo USP. VI Seminário Latino Americano de Geografia Física. Maio 2010.

INMET. Normais Climatológicas do Brasil 1991 -1990. Brasília, DF: Instituto Nacional de Meteorologia, 465p, 2009.

KAMINO, L. H. Y.; OLIVEIRA-FILHO, A. T.; STEHMANN, J. R. Relações florísticas entre a fitofisionomias florestais da Cadeia do Espinhaço, Brasil. Revista Megadiversidade, vol. 4, n. 1-2. Dezembro, 2008.

LIMA, J. E. F. W.; SILVA, C. L.; OLIVEIRA, C. A. Comparação da evapotranspiração real simulada e observada em uma bacia hidrográfica em condições naturais do cerrado. Revista Agriambi, Campina Grande - PB, UFPB , v. 5, n. 1, p.33-41, 2001.

MOURA, I. O.; RIBEIRO, K. T.; TAKAHASI, A. Amostragem da vegetação em ambientes rochosos. In: Felfili, J.M., Eisenlohr, P.V., Melo, M.M.R.F., Andrade, L.A., Neto, J.A.A.M. Fitossociologia no Brasil. Cap. 9, p. 255-294,Viçosa, MG: Ed. UFV, 2011.

NAKAJIMA, J. N.; ROMERO, R. Espécies endêmicas do Parque Nacional da Serra da Canastra, Minas Gerais. Revista Brasileira de Botânica, São Paulo, v. 22, n. 2 (suplemento), p.259-265, out. 1999.

NERI, A. V.; NETO, J. A. A. M.; SILVA, A. F.; MARTINS, S. V.; SAPORETTI JUNIOR, A. W. Composição florística de uma área de cerrado sensu stricto no Município de Senador Modestino Gonçalves, Vale do Jequitinhonha (MG) e análise de similaridade florística de algumas áreas de cerrado em Minas Gerais. Revista Árvore, v. 31, n. 6, p.1109-1119, 2007.

OLIVEIRA-FILHO, A. T.; FLUMINHAN-FILHO, M. Ecologia da vegetação do parque florestal quedas do rio bonito. Revista Cerne, v. 5, n. 2, P.051-064, 1999.

PEREIRA, A. R.; ANGELOCCI, L. R.; SENTELHAS.; P. C. Agrometeorologia; Fundamentos e Aplicações Práticas. Ed: Agropecuária - Guaíba, 478p, 2002. 
RIBEIRO, A. C.; GUIMARAES, P. T. G.; ALVAREZ, V. H. Recomendações para o uso de corretivos e fertilizantes em Minas Gerais - 5 ${ }^{\text {a }}$ Aproximação. CFSEMG - Comissão de Fertilidade do Solo do Estado de Minas Gerais. Viçosa/ MG. 1999. 359p.

RIBEIRO, J. F.; WALTER, B. M. T. Fitofisionomias do Bioma Cerrado. In Cerrado: ambiente e flora (S.M. Sano \& S.P. Almeida, eds.). Embrapa/CPAC, Planaltina, p.89-166. 2008.

ROMERO, R.; MARTINS, A. B. Melastomataceae do Parque Nacional da Serra da Canastra, Minas Gerais, Brasil. Revista Brasileira de Botânica, v. 25, n. 1, p.19-24, mar. 2002.

ROSENBERG, N. J.; VERMA, S. B.; BLAD, B. L. The radiation Balance. In: Climate: the biological environment. Ed: John Wiley \& Sons, United States of America, p. 5-94, 1983.

RIGONATO, V.D.A. A dimensão sociocultural das paisagens do cerrado goiano: o distrito de Vila Borba. ALMEIDA, M.G. de (Ed). Tantos Cerrados: múltiplas abordagens sobre a biogeodiversidade e singularidade sociocultural. Goiânia: Ed. Vieira, p.63-95. 2005.

SANTANA, D. G.; RANAL, M. A. Análise da germinação: Um enfoque estatístico. Ed: UnB, Brasília, 248p, 2004.

SELLERS, W.D. Physical Climatology. Chicago: The University of Chicago Press, 272p. 1974.

SOUZA, M.J.H.; CUPOLILLO, F. Direção Predominante e da Velocidade do Vento Diurno e Noturno em DiamantinaMG. In: Congresso Brasileira de Meteorologia 2012, Gramado-RS. Anais. Gramando - RS: Sociedade Brasileira de Meteorologia CD-ROM, 2012.

THOMAS, D. S.; EAMUS, D.; SHANAHAN, S. Influence of season, drought and xylem ABA on stomatal responses to leaf-to-air vapour pressure difference of trees of the Australian wet-dry tropics. Australian Journal of Botany, v. 48: 143-151, 2000.
THORNTHWAITE, C. W.; MATHER, J. R. The water balance. Centerton, NJ, USA: Drexel Institute of Technology, vol. 8, 1955.

VIEIRA, J. P.G.; SOUZA, M. J. H.; TEIXEIRA, J. M.; CARVALHO, F. P. Estudo da precipitação mensal durante a estação chuvosa em Diamantina, Minas Gerais. Revista Agriambi, Revista Brasileira de Engenharia Agrícola e Ambiental, Sociedade Brasileira de Engenharia Agrícola e Ambiental. Campina Grande - PB. v. 14, n. 7, p.762767, 2010. Versão On-line. ISSN 1415-4366. http:/www. agriambi.com.br

VOIGT, A. R. A.; SOFFIATTI, P.; FILHO, M. T.; LISI, C. S.; BOEGER, M. R. T. Anatomia comparada do lenho de Caryocar brasiliense (Caryocaraceae) em fisionomias de cerradão e cerrado sensu stricto. Revista Rodriguésia, vol. 61, n. 4, 603-613. 2010.

VOURLiTIS, G. L.; NOGUEIRA, J. S.; LOBO, F. A.; SENDALL, K. M.; DE PAULO, S. R.; DIAS, C.A.A.; PINTO JR.; O.B.; ANDRADE,N.L.R. Energy balande and canopy conductance of a tropical semi-deciduos forest of the Southern Amazon Basin. Water Resources Research, v. 44, 2008.

WALTER, B. M. T. Fitofisionomias do bioma Cerrado: síntese terminológica e relações florísticas. 2006. 373 f. Tese (Doutorado em Ecologia) - Instituto de Ciências Biológicas, Universidade de Brasília (UnB), Brasília. 2006.

WANG, X. P.; TANG, Z. Y.; FANG, J. Y. Climatic Control on Forests and Tree Species Distribution in the Forest Region of Northeast China. Journal of Integrative Plant Biology, vol. 48. n. 7. 2006. 